\title{
Recurrent Bile Duct Carcinoma
}

National Cancer Institute

\section{Source}

National Cancer Institute. Recurrent Bile Duct Carcinoma. NCI Thesaurus. Code C153360.

The reemergence of bile duct carcinoma after a period of remission. 